picture of the subject both theoretically and experimentally and they successfully start from an introductory level and end up with the recent developments. Supplied with these chapters a graduate student should be able to repcat most of the important work on $p-n$ diodes.

There are many chapters on superconducting tunnelling including some on Josephson junctions. The tunnelling aspect of these chapters is secondary to the superconductivity content because the tunnel junction largely provides a spectrographic technique for probing the superconducting properties of the electrodes of the junction. This technique has proved so rewarding in providing information, however, that it justifiably constitutes a major portion of the volume. Again one gets a very good picture of this subject from these chapters.

There are other chapters which do not fall into groups, such as ones on molecular excitations, zero bias anomalies, atomic tunnelling and photon assisted tunnelling, but which complete the overall picture.

Nobody reading this volume should regard it as tho gospel on tunnelling because there are a few doubtful explanations and results. For example, a more careful study of the time taken for an clectron to tunnel (chapter 1) will give a slightly longer timo than the zero time predicted. There is also some doubt that the structure on the conductance curves for $\mathrm{Bi}$ (chapter 5) is due to the band structure. Then there is the problem of the voltage potential quietly mentioned at the end of chapter 25, which is actually quite serious, and there is a wrong interpretation of the magnetic field effect on zero bias anomalies in terms of only the second order effects (chapter 27). It would be impossible, however, to write a current account of a subject that would stand for all time and the price of a few inaccuracies is certainly worth paying for this comprehensive and lively treatment of the subject.

A. F. G. WYATT

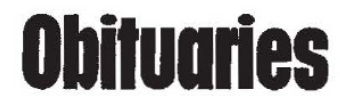

\section{Dr I. S. Stekolnikov}

I. S. Stekolnikov, of the Krzhizhanovsky Institute, Moscow, who died on August 31 after a long illness, was known to many physicists and electrical engineers for many papers on the high voltage electrical discharge, and for his book on lightning and sparks.

Ilja Samuilovich Stekolnikov was born in Tashkent in 1905 , the son of a doetor, and graduated from the Technical High School in Moscow. He began his postgraduate work in the All-Union Electrotechnical Institute, Moscow, then under the directorship of Professor Sirotinsky. Stekolnikov submitted his dissertation for a doctorate on the cathode-ray oscillograph and its applications, and then went to Professor Rogowski's laboratory at the Technical Institute in Aachen, to work on high voltage oscillography.

In 1935 he was made head of tho High Voltage Laboratory of the G. M. Krzhizhanovsky Institute and created a school of gas-discharge studies known throughout the world. In 1936 he went to work in the High Voltage Laboratory of the Metropolitan-Vickers Company at Trafford Park, a year or so after work had begun on the million-volt spark with a rotating camera.

$\mathrm{He}$ began to study the spark discharge in 1937 and continued this work for thirty years, using ever more advanced techniques. He established the leader-stroke to the long spark in Russia, and was the first to use the electro-optical shutter to exclude the intense light of the main stroke. He was also the first to use the image intensifier camera to record the very weak components of the leader-stroke. With colleagues he was also the first to appreciate the great difference in spark-over voltage of gaps when stressed with surges with very long wavefronts, and present knowledge of the dotails of the breakdown process in these conditions is due chiefly to the work of his school. Members of his laboratory published about two hundred scientific papers during the thirty yoars of his leadership, and he was awarded a state Prize of the USSR. Before the Second World War he organized field investigations of lightning, and new work in connexion with this had been started before his death. It involved photographing lightning to a tall building from a neighbouring skyscraper, as MeEachron did in 1938 in New York.

Although some of his overseas colleagues were able to keep up eontinuous correspondence with him, Stekolnikov never went further than the countries of the Warsaw Pact to attend intornational conferences.

\section{Correspondence}

\section{The EMBO Question Debated}

SrR,--In your centenary issue (Nature, 224, 406; 1969), you report on a recent meeting which you acknowledge to have been hold in private, and you are doing so against the explicit wishes of its chairman. I note that you apologize "to those among the participants who may be surprised to see their opinions appear in print". No need to apologize to me on these grounds; for the opinions which you ascribe to me are not the ones I hold, nor are they related-except inversely-to what I said at the meeting.

Yours faithfully,

Department of Biophysies,

B. Katz

University College London,

Gower Street,

London WCI.

A faulty teiephone lins between the Nature office and a place outside London cannot excuse our correspondent's failure to hear a vital "not" in an account of what Sir Bernard Katz said at the meeting. It is understood that Sir Bernard felt that his colleagues were being used by the politicians to gain a foothold in Europe, as we reported, and that they should not allow themselves to be so uscd. It is therefore wrong to count Sir Bernard among the supporters of the EMBO laboratory, and we must apologize for any cmbarrass-
ment he has been caused. Editor, Nature.

\section{Cyclamates}

Sir,-Your leading articles on cyclamates reveal a surprising lack of appreciation of the composition and role of the Food Additives and Contaminants Committee that I feel I must correct.

Contrary to your statement (Nature, 224, 298; 1969), food companies are not represented on the committer. The members are mainly drawn from universities, hospitals, and industry, but all serve in a personal capacity. Both they, and the members of the Pharmacology Sub-Committee, give advice as independent experts on matters reforred to them by ministers. Neither body would submit, as your article of November 1 seems to imply (Nature, 224, 298; 1969), to manipulation by politicians.

You refer to all-day joint sessions to discuss the new evidence from America; in fact the meeting lasted two hour's. You are clearly critical of the advice given afterwards that it would be prudent to suspend the use of cyclamates until the results of further investigations 